\title{
Changes in public knowledge and perceptions about antibiotic use and resistance in Jordan: a cross-sectional eight- year comparative study
}

\author{
Suzanne Abdelmalek * ${ }^{*}$, Rowan AlEjielat, Walid Abu Rayyan, Nidal Qinna and Dana Darwish
}

\begin{abstract}
Background: Resistance to antibiotics is a growing problem, worldwide and particularly in developing countries like Jordan. Raising public awareness on appropriate antibiotic use is crucial to combat this problem. The current study describes the change in public Knowledge and attitudes towards the use of antibiotics over a period of 8 years.

Methods: Two cross-sectional studies were performed 8 years apart on Jordanians of different age groups, and social settings, residing in Amman, Jordan. Convenience non-probability sampling techniques were used. In 2010, a questionnaire was distributed in paper form, whereas in 2018 snowball sampling was used to disseminate an identical electronic questionnaire. Chi-square test and post hoc analysis were done using the z-test to compare column proportions, adjustment for multiple testing using the Bonferroni method. Multiple logistic regression was used to adjust for case mix for each survey. Comparisons were made across the two studies and within each study.

Results: A total of 711 participants in 2010 and 436 participants in 2018 were surveyed. Over the 8-year period, there was a significant improvement in the beliefs regarding the use of antibiotics such as disagreeing to keeping left over antibiotics for later use from 57 to $70 \%(p<0.05)$ and disagreeing to buying antibiotics without physicians' consent increased from 80 to $89 \%$ ( $P$ value $<0.001)$. There was no significant change in the beliefs that support self-medication such as: using antibiotics from a friend (72 to 77\%) buying antibiotics without a prescription (42 to $45 \%)$, and getting information about medication use from leaflet without referring to a health care professional (60 to 63\%). There were some areas of confusion regarding antibiotic range of effectiveness, and origin of resistance. Agreement about antibiotic resistance being a problem in Jordan increased significantly from 44 to $60 \%$ ( $p<0.001$ ). In addition, there was a significant increase in the percentage of participants who said that they don't request antibiotics from physicians (56 to 75\% $(P \leq 0.001)$ and who said they would trust physicians' decisions about the necessity of antibiotics (70 to $83 \% P<0.05$ ).
\end{abstract}

Conclusion: Findings indicate the need for better suited, and more inclusive, public educational campaigns.

Keywords: Antibiotic, Resistance, Awareness, Beliefs, Knowledge, Perception, Comparison study

\footnotetext{
* Correspondence: sabdelmalek@uop.edu.jo

Faculty of Pharmacy and Medical Sciences, University of Petra, Amman,

Jordan
}

(c) The Author(s). 2021 Open Access This article is licensed under a Creative Commons Attribution 4.0 International License, which permits use, sharing, adaptation, distribution and reproduction in any medium or format, as long as you give appropriate credit to the original author(s) and the source, provide a link to the Creative Commons licence, and indicate if changes were made. The images or other third party material in this article are included in the article's Creative Commons licence, unless indicated otherwise in a credit line to the material. If material is not included in the article's Creative Commons licence and your intended use is not permitted by statutory regulation or exceeds the permitted use, you will need to obtain permission directly from the copyright holder. To view a copy of this licence, visit http://creativecommons.org/licenses/by/4.0/. The Creative Commons Public Domain Dedication waiver (http://creativecommons.org/publicdomain/zero/1.0/) applies to the data made available in this article, unless otherwise stated in a credit line to the data. 


\section{Background}

Antibiotics have been used to treat infections since the early twentieth century [1]. However, excessive, and unnecessary use have resulted in the development of resistance towards their effect [2]. This problem is well known to scientists who work in the field, on the contrary, a considerable proportion of the public remain unaware of it $[3,4]$. In developing countries, antimicrobial misuse and abuse are evident. Generally, most antimicrobials can be freely purchased from community pharmacies without a medical prescription. Patients quite often do not comply to the correct dose, omit doses, or combine antibiotics with herbs believing that it would improve their effect [5].

Antimicrobial resistance (AMR) is growing at an alarming rate, hence it mandates intervening at different levels to effectively combat it. Efforts should be geared at the community level as well as the professional bodies, involving political, medical, veterinary, agricultural, industrial or environmental societies [6]. The public plays an important role in the emergence, spread and control of bacterial resistance to antibiotics [7]. This was highlighted in the World Health Organization (WHO) Global Strategy for Containment of Antimicrobial Resistance in 2001 [8], where factors contributing to antimicrobial resistance were identified. These were patients' misperceptions, self-medication, poor adherence to dosage regimens and advertising and promotion [8]. As a remedy, educational activities were recommended to raise Knowledge on the appropriate use of antimicrobials, the importance of prevention measures such as immunization, vector control, handwashing, food hygiene, etc., and use of suitable alternatives to antimicrobials for the relief of symptoms. Furthermore, activating measures to encourage health care seeking behavior and prohibit self-initiation of treatment [8]. The WHO global action plan to tackle antimicrobial resistance (2015) listed several objectives to reach this aim. First, to take immediate measures to raise awareness of antimicrobial resistance and promote behavioral change, through public communication programs that target different audiences as well as consumers [9]. In Jordan, the Ministry of Health $(\mathrm{MoH})$ along with WHO and academic institutes have been collaborating to raise public awareness on the proper use of antibiotics. Social media platforms have been widely leveraged for health promotion and launching of health awareness campaigns. Publishing awareness content on social media might allow international distribution and an indefinite exposure period [10]. Many studies assessed the behavior regarding antibiotic use in Jordan [11-17]. The current study, however, is a comparison report of Knowledge and perceptions about antibiotic use and resistance in Jordan across 8 years. It was conducted on a sample from the city of Amman (the capital of Jordan) in 2010 and another sample in 2018. We aimed at observing the change in public Knowledge and attitudes towards the use of antibiotics over the period of 8 years. We expected the public awareness towards antimicrobial resistance to improve as a consequence of the programs implemented by the government and $\mathrm{WHO}$, which also coincided with the increased use of social media platforms over the past years.

\section{Methods}

Two cross sectional studies were performed 8 years apart. The first study was conducted between July-August 2010, which involved using paper-based questionnaire. The second study was conducted between July - August 2018, involving an electronic survey. The questionnaires were identical and distributed to two unrelated populations.

The study included a sample of Jordanians residing in Amman, the capital city of Jordan. Convenience nonprobability sampling was used. The paper-form questionnaire involved trained researchers who approached possible participants from multiple sites. The study sites included community pharmacy customers, coffee shops customers, students at universities etc. Participants' consent was obtained prior to answering the questionnaire. Snowball sampling was used for the distribution of the electronic questionnaire in 2018. A link to the survey was sent to Facebook and WhatsApp groups, both professional and non-professional, initially, then each group was asked to send the questionnaire to other acquaintances regardless of education, gender, or occupation in sought of randomness. A brief description of the study and its aims was included in the beginning of the electronic survey and filling the questionnaire was considered as participant's consent.

A sample size calculation based on a $95 \%$ confidence level, 5\% margin of error and 0.5 estimated anticipated frequency in a population of around 1.5 million in Amman resulted in a minimum of 384 surveys to be collected for each year, however additional questionnaires were collected in both surveys to reduce bias.

\section{Design and development of questionnaire}

Relevant literature was reviewed, and the questionnaire was compiled by two clinical pharmacists and a microbiologist. The questionnaire was designed in the Arabic language, to prevent any vagueness and was tested before administration to the public on a sample of 10 friends and family members. English version of the questionnaire is available as Additional file 3.

The questionnaire consisted of 22 questions. Three demographic questions. Thirteen questions in the form of statements for which the participants could choose an answer of either "I agree", "I do not agree", or "I do not 
know". Three multiple choice questions, one "yes", "no", or "I don't know" question, and two multi-answer questions (e.g. questions on indications of antibiotics and consequences of antimicrobial resistance).

The first part enquired about demographics, involving gender, age, and medical insurance. The second part asked about antibiotic use by participants (8 questions): ability to name an antibiotic, frequency of antibiotic use over the past 12 months, obtaining antibiotics from friends or relatives without consulting a physician, ability to obtain information on antibiotic use from drug leaflet versus a medical professional, keeping leftover antibiotics for future use, purchasing antibiotics without a prescription, completion of antibiotic regimen, and buying antibiotic against doctors' recommendation. The third part also consisted of 8 questions. It asked about awareness of antibiotics action, indications for use, causes and consequences of antimicrobial resistance and the seriousness of the antimicrobial resistance problem in Jordan. In more detail, participants were asked if antibiotics work on bacteria or viruses, then they were presented with two sentences concerning the effect of antibiotics on common cold and were asked if they agreed or disagreed with the sentence or if they didn't know the answer. They were also presented with a multiple answer question that contained possible indications for antibiotics. To assess Knowledge about resistance, participants were presented with two phrases that inquire about the origin of antibiotic resistance, a multianswer question that asks about possible consequences of antibiotic resistance, and one phrase about the current status of antibiotic resistance in Jordan. The fourth and last part consisted of 3 questions concerned with the interaction between participants and physicians relevant to antibiotics use: requesting antibiotics from physicians, trusting the physicians' decisions when not having antibiotics prescribed, and patients opinion about the physician who doesn't prescribe antibiotics. Participants were asked to answer sincerely. The survey was anonymous, and no monetary compensation was given.

\section{Statistical analysis}

Data were analyzed using the statistical software SPSS version 25. Descriptive analysis using frequencies and percentages was performed, as well as testing for statistically significant association between sample demographics and the level of awareness of antimicrobial resistance. Comparisons were done across the two studies and within each study. Statistical significance was determined using the chi-square test. Alternatively, Fisher exact test was used when criteria for chi-square test was not met. Post hoc analysis was done using the z-test to compare column proportions, adjustment for multiple testing using the Bonferroni method was also performed. A $P$-value of 0.05 was considered significant. Multinomial logistic regression was used to adjust for case mix for each survey, gender and insurance were included in the model as confounders. Outcome was reported as odds relative to the correct answer. Missing data were deleted from analysis as they were considered missing at random and expected not to introduce bias in the analysis. In 2010 The percent of missing data was less than $5 \%$ for all questions except for one question where it reached $7.6 \%$. There were no missing data in 2018 since the questionnaire was submitted electronically.

\section{Results}

\section{Demographics}

A total of 711 participants in 2010 (50\% males and 50\% females) and 436 participants in 2018 (30.96\% males and $69.04 \%$ females) were studied. Demographics are shown in Table 1.

\section{Beliefs and attitudes towards antibiotic use}

Eighty-three percent of our sample knew a name of an antibiotic in 2010 compared to $95.5 \%$ in 2018 . One third (32.1\%) of participants used antibiotics once in the previous year in 2010 compared to $55.5 \%$ in 2018 ( $P$ value $<0.05)$. In addition, participants who used antibiotics three times or more dropped significantly from $34.6 \%$ in 2010 to $20.1 \%$ in 2018 with no significant differences observed after adjusting for gender and insurance.

Table 2 summarizes participants' attitudes towards antibiotic use in both studies stratified by gender and

Table 1 Demographics

\begin{tabular}{lll}
\hline Variable & $\mathbf{2 0 1 0}$ & $\mathbf{2 0 1 8}$ \\
\hline Gender & & $135(30.96 \%)$ \\
Male & $356(50.01 \%)$ & $301(69.04 \%)$ \\
Female & $355(49.9 \%)$ & 436 \\
Total & 711 & \\
Age (years) & & $164(37.6 \%)$ \\
$\leq 29$ & $418(58.79 \%)$ & $104(23.9 \%)$ \\
$30-39$ & $148(20.82 \%)$ & $84(19.3 \%)$ \\
$40-49$ & $73(10.27 \%)$ & $84(19.3 \%)$ \\
$\geq 50$ & $49(6.89 \%)$ & 436 \\
Missing & $23(3.23 \%)$ & \\
Total & 711 & $296(67.9 \%)$ \\
Medical Insurance & & $140(32.1 \%)$ \\
Yes & $428(60.2 \%)$ & 436 \\
No & $275(38.7 \%)$ & \\
Missing & $8(1.13 \%)$ & 711 \\
Total & &
\end{tabular}




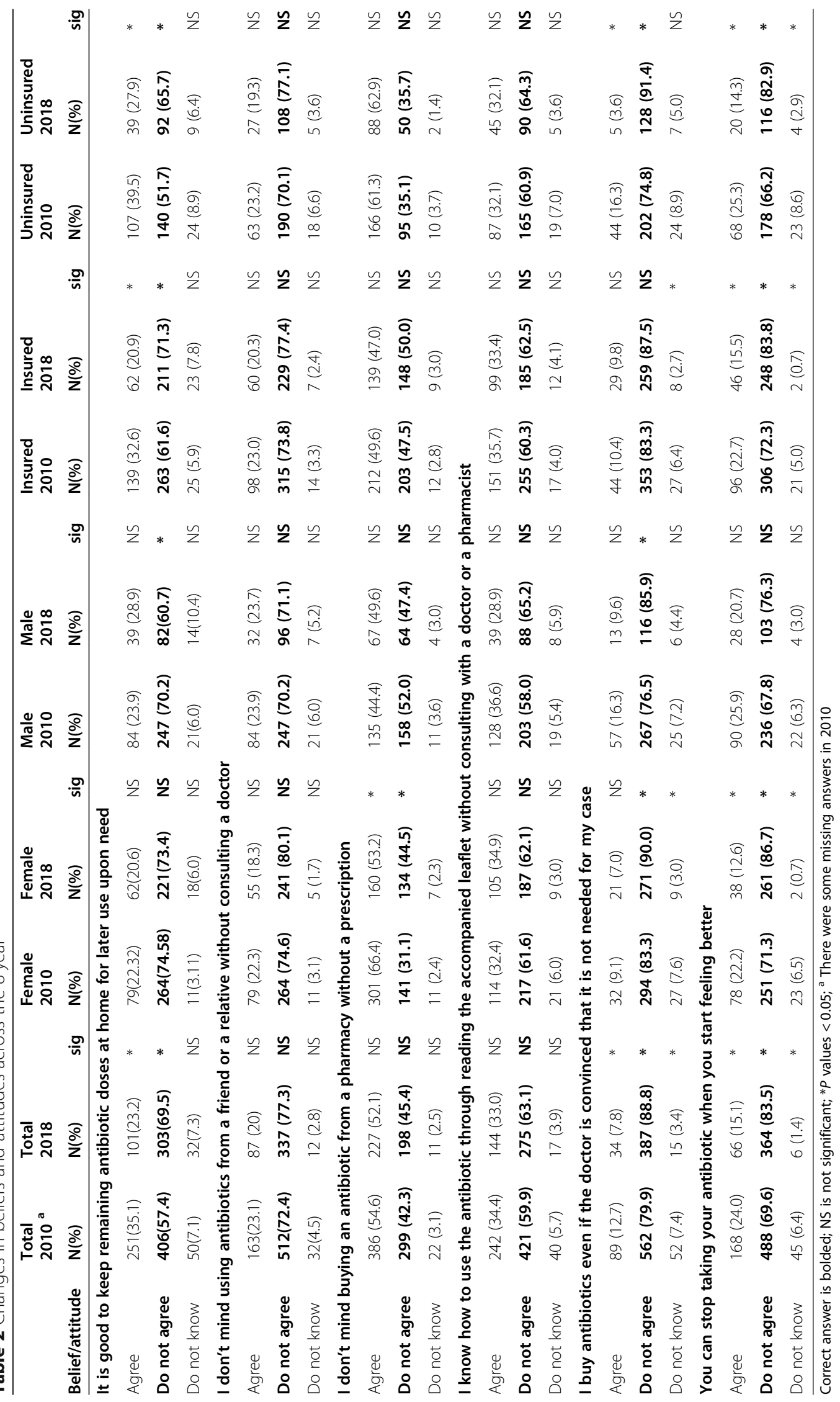


insurance status. Please refer to additional files (Table A, Table B) for full description of the analysis.

When participants were asked if they agreed with the statement "It is good to keep remaining antibiotic doses at home for later use upon need" there was a significant change in opinions between 2010 and 2018. The percent of participants $(69.5 \%)$ who disagreed to the statement in 2018 significantly exceeded those in 2010 (57.4\%). Females $(73.4 \%)$ significantly exceeded males $(60.7 \%)$ in their correct answer in $2018(P<0.05)$ but not in 2010 $(P=0.12)$. However, after adjusting for insurance status, males in 2010 were 1.43 times more likely than females to agree with the sentence, 95\% CI (1.031-1.969), $p=$ 0.032 . And in 2018 males were 1.7 times more likely than females to agree with the sentence, 95\% CI (1.0412.694) $P=0.034$. When adjusted for gender the insured were less likely to agree with the sentence in 2010 (odds $0.657,95 \%$ CI (0.472-0.915), $P=0.013 \%$ but not in 2018 .

When participants were asked whether they agreed with the statement "I don't mind using antibiotics from a friend or a relative without consulting a doctor "the majority of participants in both years disagreed. The percentages were 72 and $77 \%$ for 2010 and 2018, respectively, with a $5 \%$ increase in people who disagreed across the 8 years. Females-positive responses $(80.1 \%)$ significantly exceeded male-responses $(71.1 \%)$ in $2018(P<$ $0.05)$ but not in $2010(P=0.146)$. After correcting for insurance status, there were no differences between males and females on the "agree" answer. But males were 2.36, and 3.47 times more likely to answer "I do not know" in 2010 and 2018 respectively $(P=0.027,0.038)$. Insured participants after correcting for gender were less likely to answer I do not know in 2010 (odds 0.414, 95\% CI $(0.199-0.861, P=0.018)$ but not in 2018,2010 were 1.43 times more likely than females to agree with the sentence, 95\% CI (1.031-1.969), $p=0.032$. And in 2018 males were 1.7 times more likely than females to agree with the sentence, 95\% CI (1.041-2.694) $P=0.034$. When adjusted for gender the insured were less likely to agree with the sentence in 2010 (odds 0.657, 95\% CI (0.472-0.915), $P=0.013^{*}$ but not in 2018.

No significant change was found across the years in opinions regarding buying antibiotics from a pharmacy without a prescription. Those who disagreed with the sentence regarding antibiotic purchase without a prescription constituted $42.3 \%$ in 2010 and $45.4 \%$ in 2018 . However, a statistically significant difference was observed when responses were stratified by medical insurance status. In both years insured participants significantly disagreed to the statement compared to uninsured ones $(49.6 \%$ vs $35.5 \%$ in 2010 $(P<0.05)$ and $50 \%$ vs $35.7 \% \quad(P<0.05)$ in 2018$)$. Which remained significant after correcting for gender. Interestingly, female correct responses significantly $(P<0.05)$ increased over the years while males' correct responses did not.

Over half of participants in both years disagreed with the statement "I know how to use the antibiotic through reading the accompanied leaflet without consulting with a doctor or a pharmacist", $59.8 \%$ in 2010 compared to 63\% in 2018 with no significant difference between responses in the 2 years, even after correcting for confounders.

The percentage of participants who disagreed with the statement "I buy antibiotics even if the doctor is convinced that it is not needed for my case" increased significantly from $79.9 \%$ in 2010 to $88.8 \%$ in 2018 ( $P$ value $<0.001)$. Females percentage $(83.3 \%)$ significantly exceeded that of male percentage $(76.5 \%)$ in $2010(P<$ $0.05)$, but there was no significant difference between them in 2018. This remained significant after adjusting for insurance, males were 2.19 times more likely to agree in $2010(95 \% \mathrm{CI} 1.36-3.52, P=0.001)$ but there was still no difference in 2018. A statistically significant $(P<0.05)$ difference in the answers to this question was observed between age groups in 2018 (92.7\% of the age group $\leq 29$ disagreed with the sentence, $90.4 \%$ of the age group 30 $39,85.7 \%$ of the age group $40-49,82.1 \%$ of the age group 250 ). Having a medical insurance seemed to influence answers to this question. In 2010, $83.3 \%$ of people who were insured did not agree with the statement compared to $74 \%$ of those not insured. However, in 2018, $87.5 \%$ of people who were insured did not agree with the statement, compared to $91.4 \%$ of people who were not insured. These differences were significant in both years after correcting for gender. Insured people were less likely to agree to the sentence, i.e. they didn't buy antibiotic if the Dr. didn't think it is needed in 2010, (odds $0.0507,95 \%$ CI $(0.319-0.805), P=0.004)$ but in 2018 insured participants were 3 times more likely to agree to the sentence (odds 2.918, 95\% CI (1.102-7.729), $P=0.031$ ).

The percentage of people who disagreed with the statement" you can stop taking your antibiotic when you start feeling better" increased significantly $(P<0.001)$ from $70 \%$ in 2010 to $83 \%$ in 2018 . Females' correct response (86.7\%) exceeded males' correct responses (76.3\%) significantly $(P<0.05)$ in 2018 but not in 2010.

\section{Knowledge about antibiotics effects and causes of resistance}

\section{A. Knowledge about antibiotic range of effectiveness and indications.}

The percent of people who knew that antibiotics are effective against bacteria increased significantly from $33 \%$ in 2010 to $58 \%$ in $2018(p<0.001)$. Females 37\% 
significantly answered more correctly compared to males $29.9 \%$ in 2010 ( $P$ value $<0.05$ ), but there was no difference between them in 2018 (57.8\% vs $58.8 \%$ for males and females respectively). The percent of people who stated that it is effective against viruses also decreased significantly from $21 \%$ in 2010 to $8 \%$ in $2018(p<0.001)$ (Fig. 1a, b). A substantial percentage of participants (35.4\% in 2010 and $27 \%$ in 2018) thought that they can be used to treat both bacteria and viruses.

"Do antibiotics accelerate recovery from common cold?" Fig. 2a, shows that there was a significant $(p<0.01)$ increase in the percentage of participants who disagreed with this statement in 2018. There was a significant difference in answers to this question between age groups in $2018(P<0.05) .51 .2 \%$ of the age group $\leq 29$ disagreed to the statement $70.2 \%$ of the age group $30-39,66.7 \%$ of the age group $40-49,70.2 \%$ of the age group $\geq 50$ disagreed. There was no effect for gender even after correcting for insurance.

There was no significant change over the years in the perception of participants regarding the relation between the color of nasal discharge and the necessity for use of antibiotics (Fig. 2b). However, there was a significant variation in the percentage of correct answers between age groups in $2018(P<0.05) .20 .1 \%$ of the age group $\leq 29$ disagreed with the statement: "Runny nose accompanied by a colored discharge requires antibiotic therapy", $33.7 \%$ of the age group $30-39,28.6 \%$ of the age group $40-49,27.4 \%$ of the age group $\geq 50$. There was no effect for gender nor insurance even after correction.

Knowledge of participants about the indications of antibiotics for treating different ailments has changed significantly. The percent of people who answered that antibiotics can be used to treat common cold, toothache and gum disease, cough longer than a week, or throat pain decreased. The percent of people who answered that antibiotics can be used to treat UTI, fever, and bronchitis increased. The percent of people who answered "I do not know" decreased significantly, and lastly there was no significant change in people's opinions regarding the use of antibiotics in treating influenza (Fig. 3).

\section{B. Knowledge about antibiotic resistance}

\section{Origin of antibiotic resistance}

The percentage of participants who answered that microbes are the source of antibiotic resistance increased from $28.7 \%$ in 2010 to $37.2 \%$ in $2018(p=0.002)$ and the percentage of people who answered that the source was "human beings" decreased from $17.1 \%$ in 2010 to $10.3 \%$ in $2018(p=0.002)$. The percentage of people who did not know remained almost the same, and a considerable percentage of participants thought that resistance is formed by both microbes and man: $37.9 \%$ in 2010 and $35.8 \%$ in 2018 (Fig. 4a). Responses were not age nor gender nor insurance influenced.

"Excessive use of antibiotics increases the chance of antibiotic resistance" There was a significant increase $(p<0.001)$ in the percentage of participants who agreed with the above statement from $53.5 \%$ in 2010 to $73.9 \%$ in 2018. (Fig. 4b). There was no effect for gender nor insurance even after correction.

\section{Consequences of resistance}

When we asked about the consequences of antibiotic resistance, we had varying results (Fig. 4c). There was a significant decrease in answers to the statement "It leads to an increase in the duration of illness" and a significant increase in answers to "It leads to the use of more expensive drugs with more side effects". Which was also not influenced by age or gender.

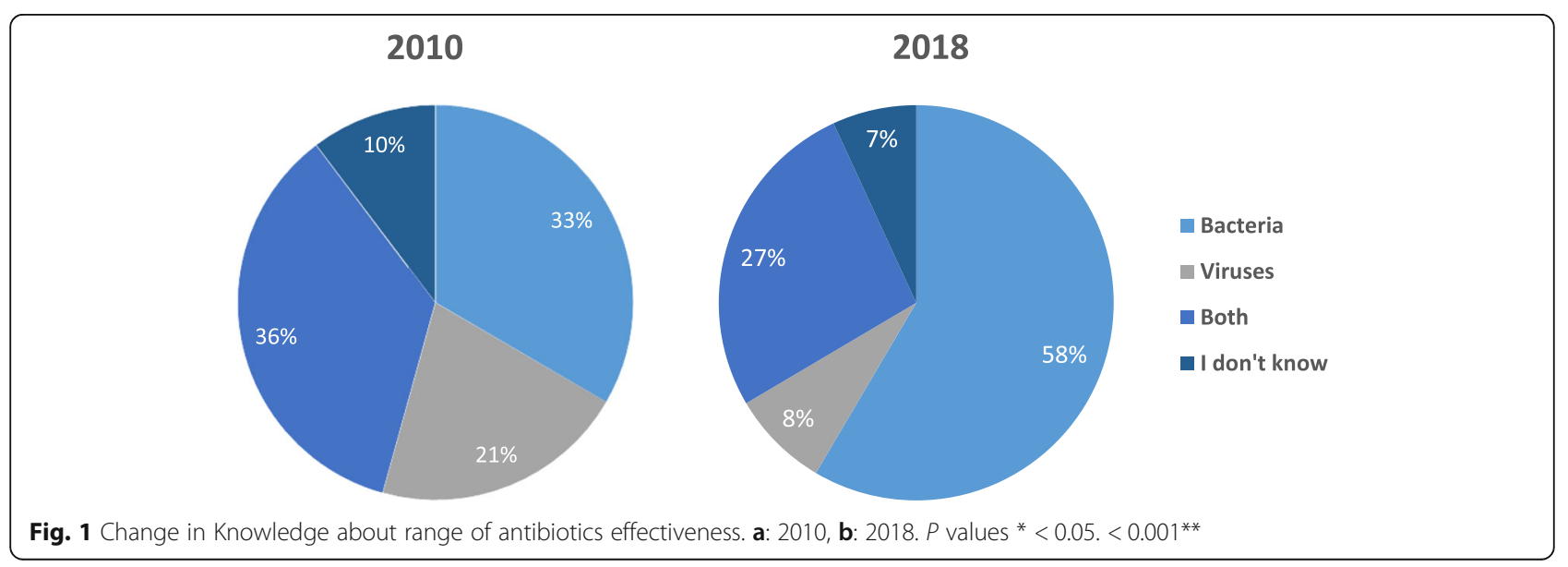




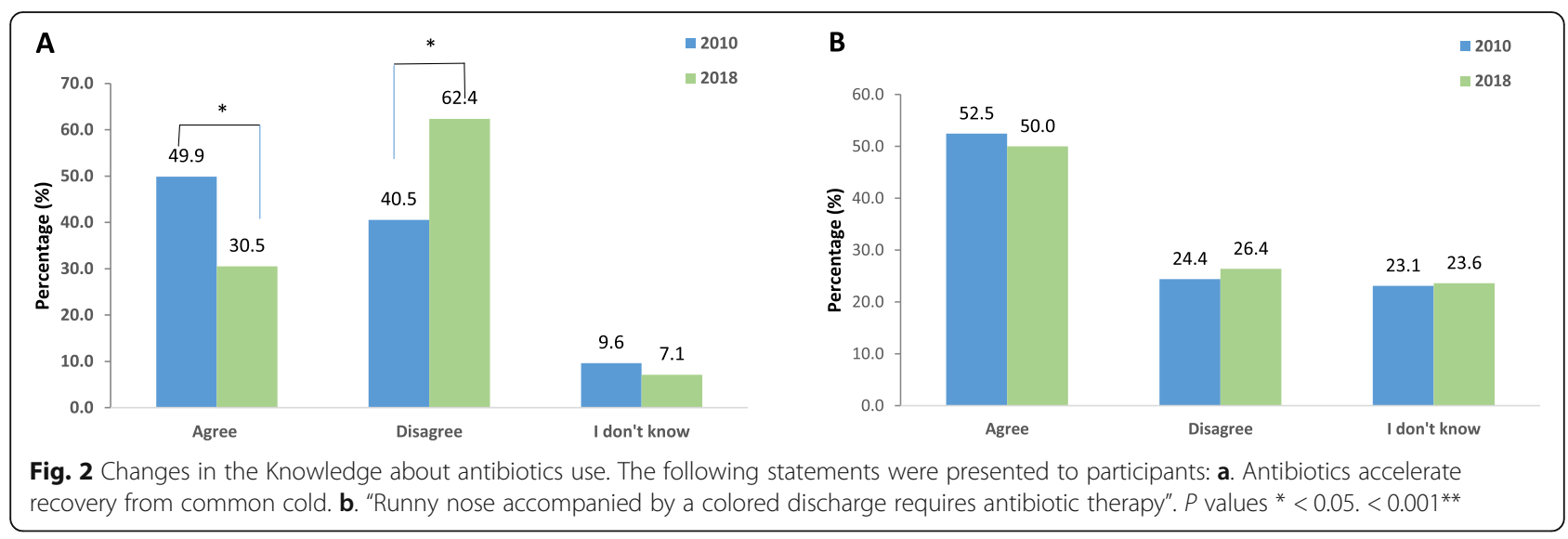

\section{Current status of resistance in Jordan}

$60.1 \%$ of the sample in 2018 agreed that antibiotic resistance is a problem in Jordan opposite to $44 \%$ in 2010 $(p<0.001)$ (Fig. $4 \mathrm{~d})$. There was no influence for gender or insurance even after correction.

\section{Patient -physician relationship}

"I ask the doctor to prescribe an antibiotic for me if he doesn't prescribe one". There was a significant increase in responses which disagree with this statement from $56.1 \%$ in 2010 to $74.8 \%$ in $2018(P \leq 0.001)$ (Fig. 5a). Males were 1.45 times more likely to agree to the sentence in 2010 (95\% CI 1.053-2.009, $P=0.023$ ) but there was no effect of gender in 2018 after correcting for insurance status.

There was also a significant change in responses to the statement "The doctor who doesn't prescribe antibiotic, when the patient believes he should, is an incompetent doctor." The percent of people who disagreed increased significantly from 67.3 to $86.2 \%(p \leq 0.05)$ (Fig. $5 b)$. A significant $(P<0.05)$ difference across age groups in 2018 was observed: $80.5 \%$ of the age group $\leq 29$ disagreed, $93.3 \%$ of the age group $30-39,82.1 \%$ of the age group $40-49$, and $92.9 \%$ of the age group $\geq 50$. After correction, males were 1.48 times more likely to agree with the sentence in 2010 (95\% CI 1.015-2.146, $P=0.042$ ) but no significant differences were found in 2018 .

There was a significant increase in percentage of people who agree with the statement "I trust the doctor's decision whether he/she prescribes an antibiotic or not". $70.1 \%$ answered "agree" in 2010 vs. $82.6 \%$ in $2018(P<$ 0.05), (Fig. 5c). This indicates a better trusting relationship with physicians over the years. This was observed to be significantly age driven in 2018 with $75.6 \%$ of the age group $\leq 29$ agreeing, $81.7 \%$ of the age group $30-39$, $85.7 \%$ of the age group $40-49$, and $94 \%$ of the age group $\geq 50(P<0.05)$. There was no influence for gender nor insurance even after correction.

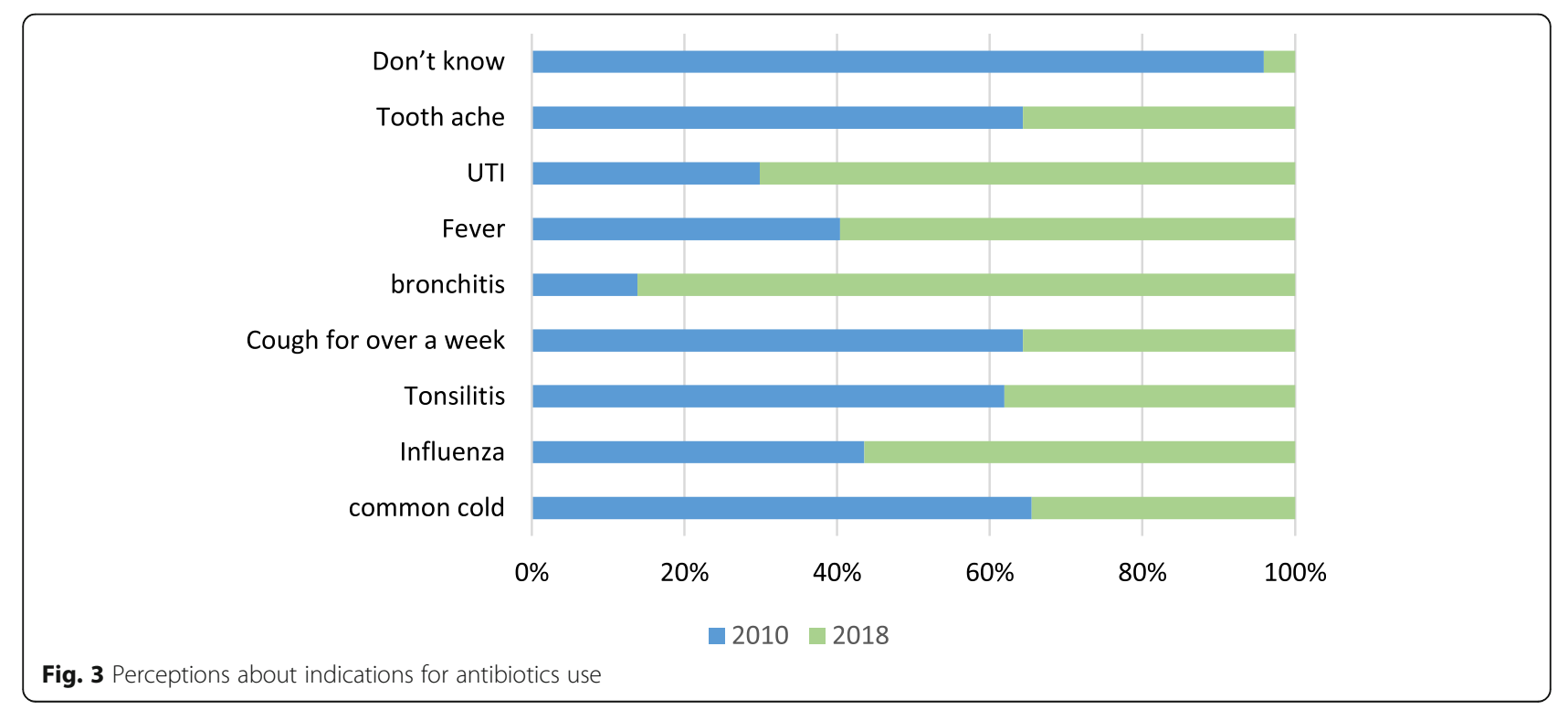




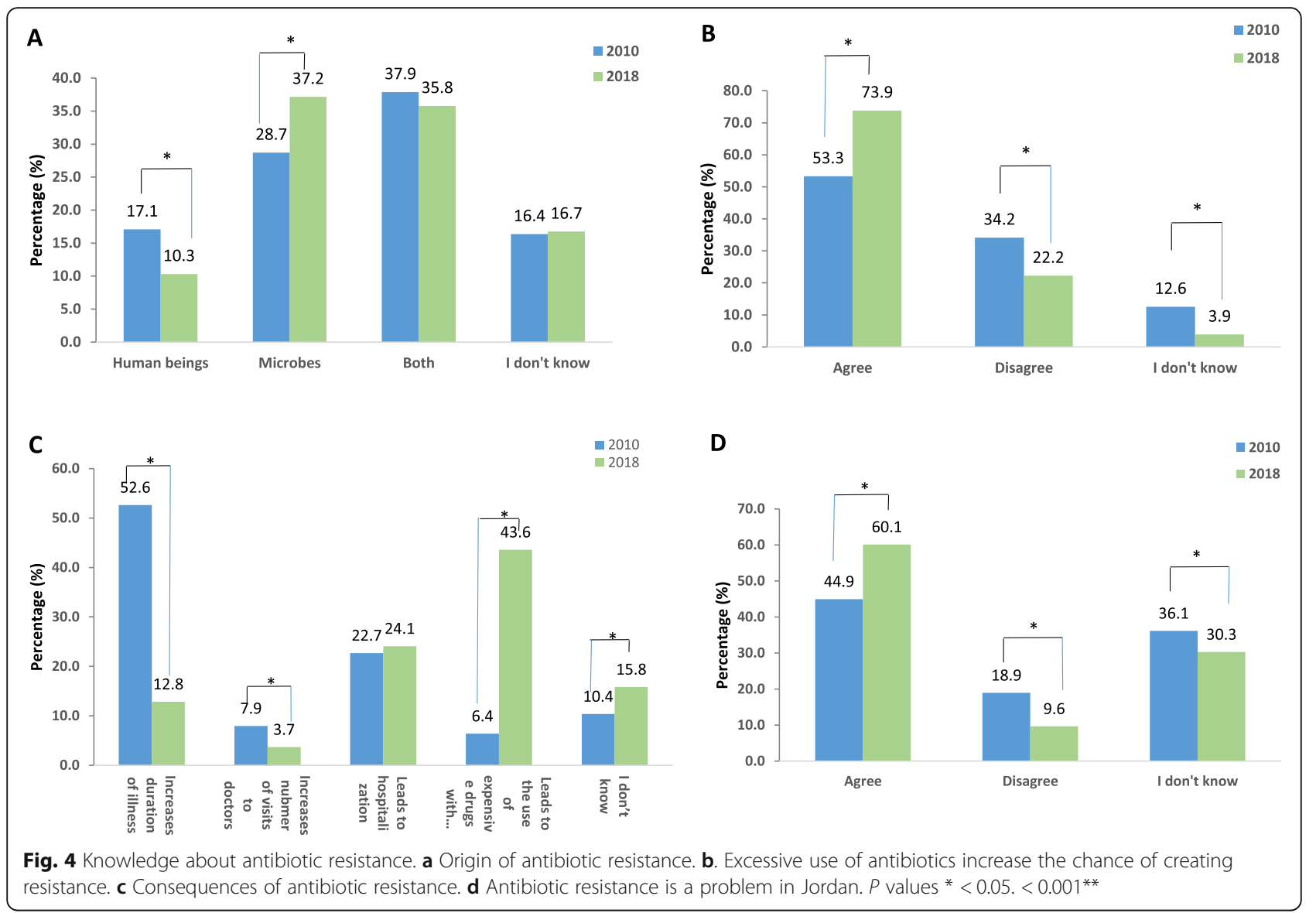

\section{Discussion}

Antibiotic resistance is a serious problem that is growing worldwide. To effectively combat antimicrobial resistance, one of the main objectives that must be achieved is to improve awareness and understanding of antimicrobial resistance through effective communication, education and training [9]. Many studies assessed public Knowledge and attitudes towards antibiotic use and resistance whether worldwide or in Jordan [11, 15, 17-21]. In the current study, comparison of public Knowledge over the years enabled characterization of the strengths and weaknesses in public awareness of antibiotic use and resistance over time. Variation in the case mix of participants in both surveys that was created with the use of different non-probability sampling techniques, was adjusted for by the use of the regression model The Snowballing technique that was used for the dissemination of the electronic questionnaire, may have resulted in sampling bias such as referral of the questionnaire to people who have similar traits or to those who utilized social media platforms used for the distribution of the questionnaire, overlooking those who choose not to use these platforms. On the other hand, possibility of bias also existed in the distribution of the paper form questionnaire by the trained researchers who selected participants at their convenience, where they approached people in their vicinity such as community pharmacy customers, coffee shops customers, students at universities etc. This also may have led to the exclusion of certain categories of people, such as those who are not able to reach mentioned places due to age, sickness or occupation. These sampling techniques may have created unavoidable underrepresentation of certain groups, which would require interpretation of the results with reservation. The findings showed improvement in awareness in some aspects and lack of change in others. The significant increase in disapproval of stopping antibiotics when symptoms improve is a positive change and conforms to another study performed in Northern Jordan, where $61 \%$ of participants believed the same [15]. On the other hand, public views in terms of purchasing antibiotics without a prescription did not change over time, which also agrees with previous studies, e.g., Shehadeh et al. (2012) in which [17] around one-third of respondents bought antibiotics directly from the pharmacy without a prescription [17]. This could be attributed to 

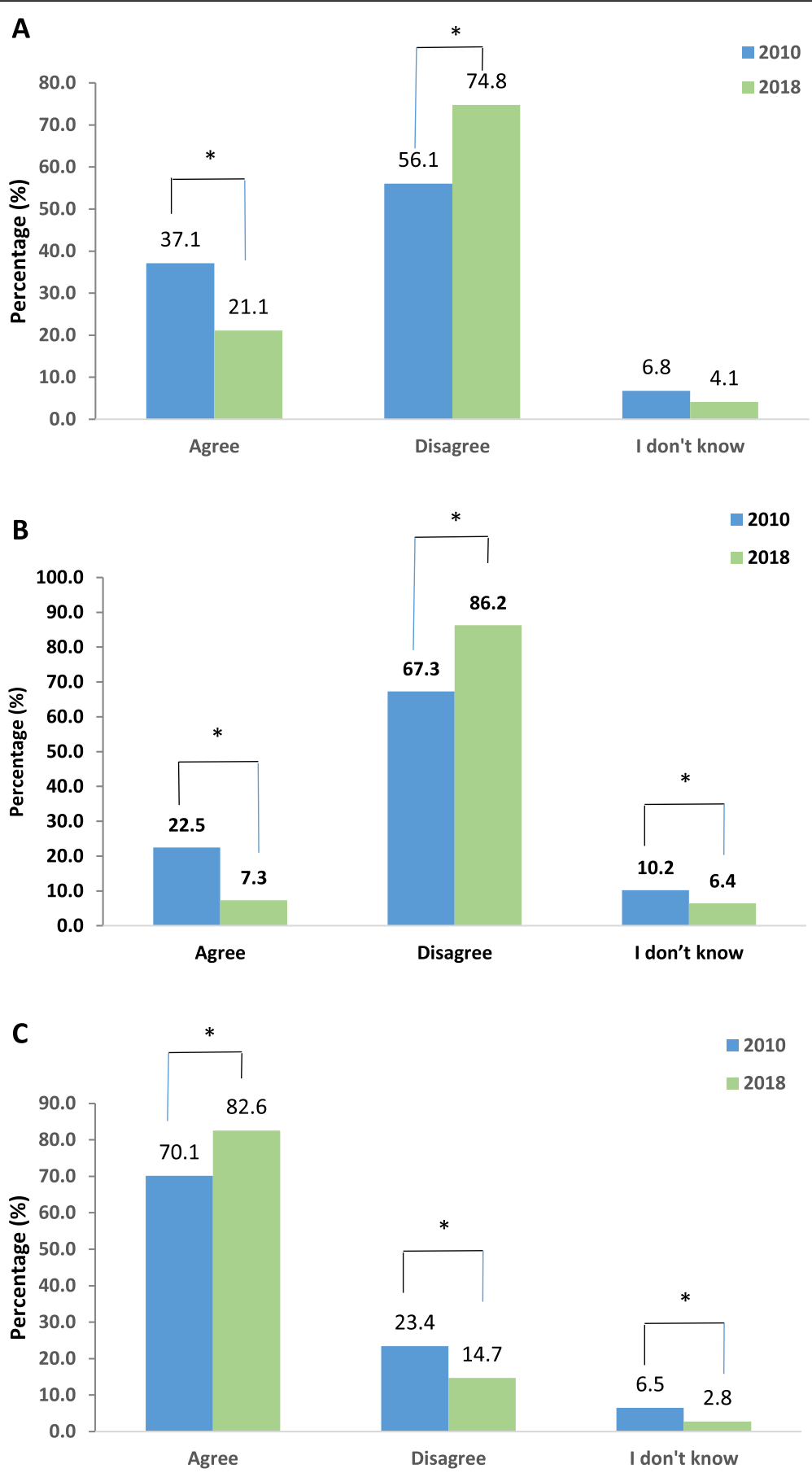

Fig. 5 Patient -Physician relationship. The following statements were presented to participants. a I ask a doctor to prescribe an antibiotic for me if he does not prescribe one. $\mathbf{b}$ The Doctor who does not prescribe antibiotic, when the patient believe he should, is an incompetent doctor. $\mathbf{c}$ I trust the Doctor's decision whether he/she prescribes an antibiotic or not. $P$ values ${ }^{*}<0.05 .<0.001^{* *}$

the unrestricted access to antibiotics from pharmacies, considering pharmacy a reliable source of information to advise on therapy, the tendency towards self-medication and relying on interpreting information in the drug leaflet to know about medication. It can also be explained by the patients' financial and insurance status. Many of those who cannot afford going to the physician prefer to consult with the local pharmacist. Findings in the current study related to medical insurance further support this explanation. As expected, those uninsured 
would agree more to buying antibiotics without a prescription compared to those insured. In Jordan, public health care facilities provide all medicines free of charge for patients with health insurance. Moreover, for those with private insurance, medical coverage and the level of copayment depend on the specific insurance policy that has been purchased [22]. Thus, it would be feasible to get antibiotics through insurance, and thereby the need to buy it without a prescription will be reduced.

The number of people who used antibiotics once over the previous year increased significantly in 2018 compared to 2010. The multiple antibiotics use significantly decreased, which was not influenced by insurance status, age, or gender. This indicated a decrease in patients' demand for antibiotics, particularly in conjunction with the evident change in beliefs on not requesting doctors to prescribe antibiotics or not perceiving doctors as incompetent if antibiotics were not prescribed.

Guidelines for the use of antibiotics for upper respiratory tract infections do not recommend using antibiotics unless bacterial involvement has been proven, and this requires a visit to a physician and a lab test [23]. The significant rise in the Knowledge of indications for antibiotics being bacterial and not viral infections is worth noting. Nonetheless, a notable proportion still thinks antibiotics are effective again both. In an earlier study by Shehada et al. [17] the authors also reported confusion regarding the range of effectiveness and use of antibiotics. Which, according to the results of the current study remained present.

The change in Knowledge about the causes and effects of antibiotics resistance was also positive. There seemed to be an increase in the Knowledge that antibiotic resistance originates in microbes; however, a considerable percentage of participants still thought that resistance originates in both microbes and man. Some misconceptions among individuals may be that since resistance starts in human beings, they would be protected if humans stop taking antibiotics. This and other misconceptions need to be emphasized and corrected in future educational campaigns.

Public awareness about the consequences of emerging antibiotic resistance have improved significantly. This was noticed primarily in the significant decrease in the percentage of participants who answered: "I don't know". Nevertheless, answers varied across the years. A direct reflection of the tightened economic status in Jordan could be seen in the change of participants' responses to the perceived consequences of the spread of antibiotic resistance. There was a significant increase in the percentage of people who answered: "It leads to the use of more expensive drugs with more side effects"; $43.6 \%$ of the people in 2018 perceived this answer as a consequence compared to $6.4 \%$ in 2010 . This change in belief could be a driving force for changing behaviors towards antibiotic use, especially when recognizing the presence of an antibiotic resistance problem in Jordan has improved significantly. Educational campaigns can undoubtedly use this information to design content to enhance public Knowledge, especially when about a third of our participants still reported that they do not know that antibiotic resistance is a problem in Jordan.

Patient pressure on physicians has always been considered a significant antibiotic misuse factor. Several studies have shown that physicians' antibiotic prescribing patterns varied in response to patient pressure and expectations $[24,25]$. In the current study, there was a significant increase in the percentage of participants who disagreed with the statement "I request the doctor to prescribe antibiotics if he didn't already do it" and those who said they trusted the Doctor's decision on the necessity of antibiotics. This response suggests an increased awareness and trust in the physician's role in determining the need for antibiotics.

We expected the age group 20-40 to report more awareness, mainly due to the increased exposure to social media. On the contrary, we noticed higher attention in the older generation (aged 60 and above). Females were generally more open to change in perceptions about antibiotic use than men.

The advancement in telecommunications over the past few years has been evident. The use of social media and the Internet became more prevalent. According to NapoleonCat. Stats, since Facebook was introduced in Jordan in 2007 and until December 2018, 5,470,000 users were registered, which accounted for $52.6 \%$ of the entire population [26]. According to Statcounter Global Stats, the most popular social media platforms in Jordan are Facebook, YouTube, and Instagram in order [27]. Many YouTube videos on proper antibiotic use and antibiotic resistance have been published online from different sources [28-30], which were also circulated on Facebook, and others were broadcasted on television and radio and disseminated in newspapers. Moreover, social media activity on the same subject has been growing in the form of short informative videos, comics, and stories about treatment failures due to infections with antibiotic-resistant strains, proper use, and consequences of improper use. Together, these social media campaigns and the efforts put forth by the $\mathrm{MoH}, \mathrm{WHO}$ and academia in Jordan could have improved public awareness on antibiotic use and resistance, as well as the physicianpatient relationship.

\section{Limitations}

The following limitations were encountered during the conduct of this comparative study. First, information on medical education was not collected in both studies. 
Even though the assumption could be made that people with health-related education would be more aware of proper antibiotic use, previous studies from Jordan showed otherwise [31].

We did not ask a specific question regarding the use of the Internet or the exposure to social media, which would hinder assessing the impact of social media campaigns.

The response rate in 2018 study could not be calculated because the tool was disseminated electronically. Only returned questionnaires were counted.

Although we attempted to correct the different participant characteristics in the two surveys by 3 -way stratification and multinomial logistic regression, we cannot assume that this sample represents the population residing in Amman. Due to these limitations, the results of this study need to be interpreted with caution.

\section{Conclusion}

These findings indicated the need for more adequate public education campaigns. These campaigns should target different age groups and multi-faceted modalities. Despite the improvement in awareness, some confusion still existed in antibiotic use and resistance. Emphasis should be laid on providing Arabic content (as Arabic is the mother tongue of most of the population), publicizing the medical websites that target non-medical people, and creating infographics that have proven to be an easy and effective way to present information [32]. Lastly, pharmacists' role in spreading awareness and education must be highlighted since they are the first point of contact by the public to purchase their antibiotics without a prescription.

\section{Supplementary Information}

The online version contains supplementary material available at https://doi. org/10.1186/s12889-021-10723-x.

Additional file 1: Table A. Chi Square test results comparing differences across the years stratified by gender and insurance.

Additional file 2: Table B. Multinomial logistic regression controlling for gender and insurance as confounders in the surveys case-mix. Odds presented as the odds of the wrong answer relative to the right answer for each possible option.

Additional file 3. Questionnaire in English version.

\section{Acknowledgements}

The authors acknowledge the Deanship of Scientific Research at University of Petra for facilitating the steps needed to conduct this research.

\section{Authors' contributions}

SMA, DD conceptualized the idea, performed the study. SMA, RA contributed in drafting and editing manuscript, RA, WA contributed in data analysis, NQ: contributed in providing and interpreting the raw data, All authors contributed to revised versions of the manuscript. All authors read and approved the final manuscript.
Funding

None.

\section{Availability of data and materials}

The datasets used and/or analyzed during the current study are available from the corresponding author on reasonable request.

\section{Declarations}

Ethics approval and consent to participate

This study was granted approval from the Board of Scientific Research at the University of Petra, Jordan. All participants were requested to sign a consent form that explained the study's aims and the confidentiality of information. Agreement to fill in the electronic version of the questionnaire was considered consent.

\section{Consent for publication}

Not applicable.

\section{Competing interests}

The authors declare that they have no competing interests.

Received: 29 May 2020 Accepted: 29 March 2021

Published online: 19 April 2021

\section{References}

1. Zaffiri L, Gardner J, Toledo-Pereyra LH. History of Antibiotics. From Salvarsan to Cephalosporins. J Investig Surg. 2012;25(2):67-77 Available from: https:// doi.org/10.3109/08941939.2012.664099.

2. Laupland KB, Ruppé E, Harbarth S. In 2035, will all bacteria be multidrug resistant? We are not sure. Intensive Care Med. 2016;42(12):2021-3. https:// doi.org/10.1007/s00134-016-4343-2.

3. Carlet J, Collignon P, Goldmann D, Goossens H, Gyssens IC, Harbarth S, et al. Society's failure to protect a precious resource: antibiotics. Lancet. 2011;378(9788):369-71 Available from: https://doi.org/10.1016/S0140-673 6(11)60401-7.

4. Blaser MJ. Antibiotic use and its consequences for the normal microbiome. Science. 2016;352(6285):544-5. Available from: https://pubmed.ncbi.nlm.nih. gov/27126037. https://doi.org/10.1126/science.aad9358.

5. Ayukekbong JA, Ntemgwa M, Atabe AN. The threat of antimicrobial resistance in developing countries: causes and control strategies. Antimicrob Resist Infect Control. 2017;6(1):1-8.

6. Sabtu N, Enoch DA, Brown NM. Antibiotic resistance: what, why, where, when and how? Br Med Bull. 2015;116:105-13. https://doi.org/10.1093/ bmb/ldv041.

7. Davey P, Pagliari C, Hayes A. The patient's role in the spread and control of bacterial resistance to antibiotics. Clin Microbiol Infect. 2002;8(SUPPL. 2):4368. https://doi.org/10.1046/j.1469-0691.8.s.2.6.x.

8. WHO. WHO Global Strategy for Containment of Antimicrobial Resistance WHO/CDS/CSR/DRS/2001.2. 2001. p. 61-8. Available from: https://www.who. int/drugresistance/WHO_Global_Strategy_English.pdf

9. WHO. Global Action Plan on Antimicrobial Resistance. 2015. Available from: https://www.who.int/antimicrobial-resistance/publications/global-a ction-plan/en/

10. Zowawi HM, Abedalthagafi M, Mar FA, Almalki T, Kutbi AH, Harris-Brown T, et al. The potential role of social media platforms in community awareness of antibiotic use in the gulf cooperation council states: Luxury or necessity? J Med Internet Res. 2015;17(10):e233.

11. Ghadeer A. R. Y. Suaifan. A cross-sectional study on knowledge, attitude and behavior related to $\backslash$ antibiotic use and resistance among medical and nonmedical university students in Jordan. African J Pharm Pharmacol 2012; 6(10):763-770

12. Jarab AS, Mukattash TL, Nusairat B, Shawaqfeh M, Farha RA. Patterns of antibiotic use and administration in hospitalized patients in Jordan. Saudi Pharm J. 2018;26(6):764-70 Available from: https://doi.org/10.1016/j.jsps.201 8.04.009.

13. Abu-Helalah M, Alshraideh H, Hijazeen J, Al-Zu A, Abu Hassan W, Al-Sbou M. Antibiotics use and misuse among university students in Jordan. Bull Env Pharmacol Life Sci. 2015;4(5):62-71. 
14. Haddadin RN, Alsous M, Wazaify M, Tahaineh L. Evaluation of antibiotic dispensing practice in community pharmacies in Jordan: a cross sectional study. PLoS One. 2019;14(4):1-15.

15. Yusef D, Babaa Al, Bashaireh AZ, Al-Bawayeh HH, Al-Rijjal K, Nedal M, et al. Knowledge, practices \& attitude toward antibiotics use and bacterial resistance in Jordan: a cross-sectional study. Infect Dis Heal. 2018;23(1):3340 Available from: https://doi.org/10.1016/j.idh.2017.11.001.

16. Nawafleh $\mathrm{H}$, Momani M Al, Hadid L Al, Amarat W et al. Misuse of Antibiotic Therapy among University Community in South Jordan. Heal Sci J. 2016;10(6):1.

17. Shehadeh M, Suaifan G, Darwish RM, Wazaify M, Zaru L, Alja'fari S. Knowledge, attitudes and behavior regarding antibiotics use and misuse among adults in the community of Jordan. A pilot study. Saudi Pharm J. 2012;20(2):125-33. https://doi.org/10.1016/j.jps.2011.11.005.

18. Mazińska B, Struzycka I, Hryniewicz W. Surveys of public knowledge and attitudes with regard to antibiotics in Poland: did the European antibiotic awareness day campaigns change attitudes? PLoS One. 2017;12(2):1-18.

19. Awad Al, Aboud EA. Knowledge, attitude and practice towards antibiotic use among the public in Kuwait. PLoS One. 2015;10(2):1-15.

20. McCullough AR, Parekh S, Rathbone J, Del Mar CB, Hoffmann TC. A systematic review of the public's knowledge and beliefs about antibiotic resistance. J Antimicrob Chemother. 2016;71(1):27-33. https://doi.org/10.1 093/jac/dkv310.

21. Carter RR, Sun J, Jump RLP. A survey and analysis of the American public's perceptions and knowledge about antibiotic resistance. Open Forum Infect Dis. 2016;3(3):1-7.

22. Nazer LH, Tuffaha H. Health Care and Pharmacy Practice in Jordan. Can J Hosp Pharm. 2017;70(2):150-5 Available from: https://pubmed.ncbi.nlm.nih. gov/28487583.

23. Harris AM, Hicks LA, Qaseem A. Appropriate antibiotic use for acute respiratory tract infection in adults: advice for high-value care from the American College of Physicians and the Centers for Disease Control and Prevention. Ann Intern Med. 2016;164(6):425-34. https://doi.org/10.7326/M15-1840.

24. Fletcher-Lartey S, Yee M, Gaarslev C, Khan R. Why do general practitioners prescribe antibiotics for upper respiratory tract infections to meet patient expectations: a mixed methods study. BMJ Open. 2016;6(10):e012244 Available from: http://bmjopen.bmj.com/content/6/10/e012244.abstract.

25. Md Rezal RS, Hassali MA, Alrasheedy AA, Saleem F, Md Yusof FA, Godman B. Physicians' knowledge, perceptions and behaviour towards antibiotic prescribing: a systematic review of the literature. Expert Rev Anti-Infect Ther. 2015;13(5):665-80. https://doi.org/10.1586/14787210.2015.1025057.

26. NapoleonCat. stats. [cited 2020 Apr 26]. Available from: https://napoleoncat. com/stats/facebook-users-in-jordan/2019/03

27. Statcounter Global Stats. [cited 2020 Apr 26]. Available from: https://gs.sta tcounter.com/social-media-stats/all/jordan/\#monthly-200903-202004-bar

28. Youtube video How Antibiotic Resistance Happens. [cited 2020 May 17]. Available from: https://www.youtube.com/watch?v=Gki6Bm2zHa8

29. Youtube video Combating Antibiotic Resistance: Antibiotic Use. [cited 2020 May 17]. Available from: https://www.youtube.com/watch?v=C9GSIz78aDQ

30. Youtube TEd Talk Maryn McKenna: What do we do when antibiotics don't work any more?. [cited 2020 May 17]. Available from: https://www.youtube. $\mathrm{com} /$ watch? $\mathrm{v}=030 \mathrm{DpCb} 7 \mathrm{Vql}$

31. Darwish DA, Abdelmalek S, Abu Dayyih W, Hamadi S. Awareness of antibiotic use and antimicrobial resistance in the Iraqi community in Jordan. J Infect Dev Ctries. 2014;8(5):616-23. https://doi.org/10.3855/jidc.4086.

32. Siricharoen $\mathrm{W}$, Siricharoen N. Infographic utility in accelerating better health communication. Mob Networks Appl. 2018;23(1):57-67 Available from: https://doi.org/10.1007/s11036-017-0900-3.

\section{Publisher's Note}

Springer Nature remains neutral with regard to jurisdictional claims in published maps and institutional affiliations.

Ready to submit your research? Choose BMC and benefit from:

- fast, convenient online submission

- thorough peer review by experienced researchers in your field

- rapid publication on acceptance

- support for research data, including large and complex data types

- gold Open Access which fosters wider collaboration and increased citations

- maximum visibility for your research: over $100 \mathrm{M}$ website views per year

At BMC, research is always in progress.

Learn more biomedcentral.com/submissions 